\title{
Analysis of Bibliotherapy Based on Virtual Reality
}

\author{
Yang Hua ${ }^{1,}$, Wang Jingyi ${ }^{1}$, Zhang Hua ${ }^{2}$, Lu Zhangping ${ }^{1}$ \\ ${ }^{1}$ Scientific and Technical Information Institute, Jiangsu University, Zhenjiang, China \\ ${ }^{2}$ College of Agricultural Equipment Engineering, Jiangsu University, Zhenjiang, China
}

Email address:

497968074@qq.com (Yang Hua)

${ }^{*}$ Corresponding author

\section{To cite this article:}

Yang Hua, Wang Jingyi, Zhang Hua, Lu Zhangping. Analysis of Bibliotherapy Based on Virtual Reality. American Journal of Management Science and Engineering. Vol. 4, No. 5, 2019, pp. 82-86. doi: 10.11648/j.ajmse.20190405.12

Received: November 4, 2019; Accepted: November 25, 2019; Published: December 3, 2019

\begin{abstract}
Bibliotherapy uses literature as a medium, and uses reading as a means of health care and auxiliary treatment for diseases. It is a method of maintaining and restoring physical and mental health through the comprehension of the designated literature. Virtual reality is a comprehensive technology integrating computer graphics, simulation, sensing and multimedia. The combination of Bibliotherapy and virtual reality technology is feasible. Virtual reality reading uses sensing, interaction and three-dimensional graphics to create a realistic virtual world of books. Users can read books through various senses such as sight, hearing and touch. Bibliotherapy has the requirements of increasing participation, accelerating the realization of principles, and constructing the environment in virtual reality. Virtual reality Bibliotherapy is based on the goal of readers to drive, therapeutic model can achieve immersive psychological experience and deep virtual interactive experience. The promotion of virtual reality Bibliotherapy can assist the construction of social psychological harmony with low cost.
\end{abstract}

Keywords: Bibliotherapy, Virtual Reality, Aalysis, Immersive Experience, Interactive Experience

\section{Introduction}

According to Wikipedia's definition of traditional reading, "reading is a mental process in which the brain accepts information from the outside world, including words, charts, formulas, etc., and absorbs and processes it to understand the meaning of symbols." It emphasizes the fusion of mind and wisdom. Reading is a kind of cognitive activity. The body is the receptor of stimulation and the effector of behavior. Reading is mostly "up the neck" and "inside the brain [1-3]. Bibliotherapy is based on the literature media, will be read as care, health and auxiliary means for the treatment of disease, make oneself or guide others by means of literature study, discussion and understanding the content of the maintenance and restoration of a method of mental and physical health [4]. With the rise of embodied cognitive theory in the second generation of cognitive science, the concept of detached reading has been questioned. Embodied cognition emphasizes "embodied" and "contextualization". It believes that "the human body plays a key role in the cognitive process, and cognition is formed through the physical experience and its behavioral activity mode". As a kind of high-level cognitive activity of human beings, reading behavior, in the process of reading, human mind will inevitably be shaped, restricted and regulated by the body and its environment. In recent years, the development of virtual reality technology has promoted reading to become a cognitive experience of body and mind integration [5-7]. The virtual reality technology is a collection of computer graphics, simulation technology, sensor technology and multimedia technology in a body's comprehensive technology [8]. It uses interactive sensing technology and three-dimensional graphics technology to create a realistic virtual world. Users can interact with objects in the virtual environment through visual, auditory and touch senses, thus generating immersive experience and feeling. Virtual reality technology, with its unique conceivability, interactivity and immersion to users, has attracted researchers' attention and is regarded as one of the most critical technologies in the era of artificial intelligence [9].

This paper analyzes the combination of virtual reality management application and library Bibliotherapy, studies the demand, expounds the virtual reality reading technology and current situation, constructs the key points and main models of virtual reality Bibliotherapy, and summarizes the advantages 
of virtual reality Bibliotherapy management application.

\section{Demand and Status Review}

The appeal of Bibliotherapy requires virtual reality. Bibliotherapy requires readers to combine the content of the book with individual intelligence into a new psychological cognition. This is a repeated, monotonous and self-aware management process, which requires readers to have a considerable interest in reading, perseverance and management ability. The introduction of virtual reality can enhance the interest of Bibliotherapy, show the three-dimensional and interactive forms to readers, and attract readers' participation [10].

The principle of Bibliotherapy requires virtual reality. In the existing Bibliotherapy, the identification, catharsis and purification of reading are relatively slow, requiring the psychological digestion of the readers themselves. If readers can read, listen and interact at the same time, Bibliotherapy can achieve higher psychological intervention effectiveness. The immersive and interactive reading effects provided by virtual reality books allow participants in Bibliotherapy to maximize their knowledge. This is an advantage that paper books and e-books alone cannot have.

The context of Bibliotherapy requires virtual reality. The background environment of reading is one of the important factors that affect the effect of library Bibliotherapy. The famous Argentine international library director once said that the reading environment of readers is a place full of souls, and heaven should be like the library. At present, the reading background environment of paper books and e-books in libraries is restricted by the real conditions, and readers cannot experience the enjoyment freely created by many elements such as color, music and environmental art.

Virtual reality technology mainly includes simulation environment, perception, the degree of users difficult to distinguish between true and false. Simulation environment is a real - time dynamic $3 \mathrm{~d}$ realistic image generated by computer. Perception is the ideal virtual reality should have all people have the perception. In addition to the visual perception generated by computer graphics technology, there are auditory, tactile, force perception, motor perception and even smell and taste, also known as multi-perception. Natural skills are head movements, eyes, gestures, or other human behavior. The computer processes data that corresponds to the participant's actions, responds to the user's input in real time, and feeds back to the user separately. It mainly involves three research areas: (1) through computer graphics to establish a real-time three-dimensional visual effect;(2) to establish the virtual world observation interface; (3) the use of virtual reality technology to strengthen such as scientific computing technology and other applications. Virtual reality technology has the following four main characteristics: (1) multi-sensory, it is in addition to the general computer has visual perception, auditory perception, tactile perception, motion perception, and even including taste, smell, perception. The ideal virtual reality should have the perceptual function that all people have;
(2) the sense of existence, also known as immersion, it is the user feel as the protagonist in the simulation of the real degree of the environment, that is, computer technology has visual perception, and auditory perception, force perception, tactile perception, motion perception, even including taste perception, smell perception. The ideal simulation environment should have the perceptual function of all people, so that the user can hardly distinguish the true from the false. (3) interactivity, it is the degree of the participants to the simulation of the environment and the degree of natural feedback from the environment (including real-time). For example, he can grasp objects in the simulated environment directly with his hand. At this time, he can feel the hand holding things and feel the weight of the objects. (4) autonomy. In the virtual environment, according to their models, rules and the requirements of the operator, the degree of autonomous movement of things. For example, when pushed by a force, an object will move in the direction of the force, or tip over, or fall from the table to the ground.

Meng Zikui once said that "reading" is "heart to heart" and "mind to mind", which is a patient and humble attitude. The flood of information and readers' impatience in reading have given rise to the new reading technologies [11]. In 2003, Card proposed to develop virtual 3D book model through simulation books, and then added 3D virtual annotation function by extending and upgrading the model. Welch et al proposed to expand the concept of 3D virtual books into immersive virtual reality books in 2005 , and virtual reality books were first applied in medical surgery training.

In the field of library information, existing researches in China put forward the preliminary application of virtual reality technology in libraries, as well as the reading functions and effects that can be realized [12]. Virtual reality has a broad application prospect in the service innovation of library in the future [13]. Abroad, Poulter and Card have explored 3D database design, functional interaction and operation of virtual reality books. Virtual reality reading has been applied in textbooks, teaching AIDS, children's books and popular science books. Houston central library has applied augmented reality technology to improve reading experience.

National Library of China, Library of Shanghai Jiaotong University, Library of Tsinghua University, Library of Wuhan University and other institutions began to use virtual reality technology in the field of reading services, such as the construction of virtual libraries.

\section{Analysis and Discussion}

Virtual reality Bibliotherapy scene is the fusion of traditional media and virtual reality technology. It will be a new form of Bibliotherapy under the revolutionary change and in the post-library era. Its content can be processed so that the reader can be in a three-dimensional scene surrounded by all directions. The reader can freely look around the scenery, walk in it, and interact with the content in the book. Virtual reality book carrier can overcome the limitations of paper books and electronic books, and readers can get rich 
knowledge input and output in experience. It is the horizontal integration of reading and virtual reality, Internet and cloud computing, as well as a manifestation of the application of digital humanistic research. It is also the vertical integration between information technology and humanistic researchers. It is not simply the superposition of humanistic research and digital technology [14].

Characteristics of virtual reality Bibliotherapy. Virtual reality Bibliotherapy is a service driven by readers' goals to optimize readers' experience of introducing books, situational text understanding, content background knowledge, psychological analysis of characters, reading interests, etc. It is a service mode with effective participation of readers in therapy, realization of psychological intervention goals, and solving the needs of readers. The application of virtual reality in Bibliotherapy to library space reconstruction service. Virtual reality break through the original single of reading, realizes the reconstruction of the virtual space of characters, story plots, background connotation, body expressions, language movements, color music, etc. integrated with the associated key elements in the Bibliotherapy, realized the reconstruction of the virtual space of characters, story plots, background connotation, body expressions, language movements, color music, etc. It realizes the reconstruction of virtual space of characters, story plots, background connotation, body expressions, language movements and color music. It presents the comprehensive scene of the reading object to the reader in a visual way to overcome the Bibliotherapy obstacle caused by the reader's low acceptance and single thinking. Virtual reality Bibliotherapy is a value-added service, which constructs the environment of participants, the environment of books and the environment of works, and endows the conventional Bibliotherapy with more service value.

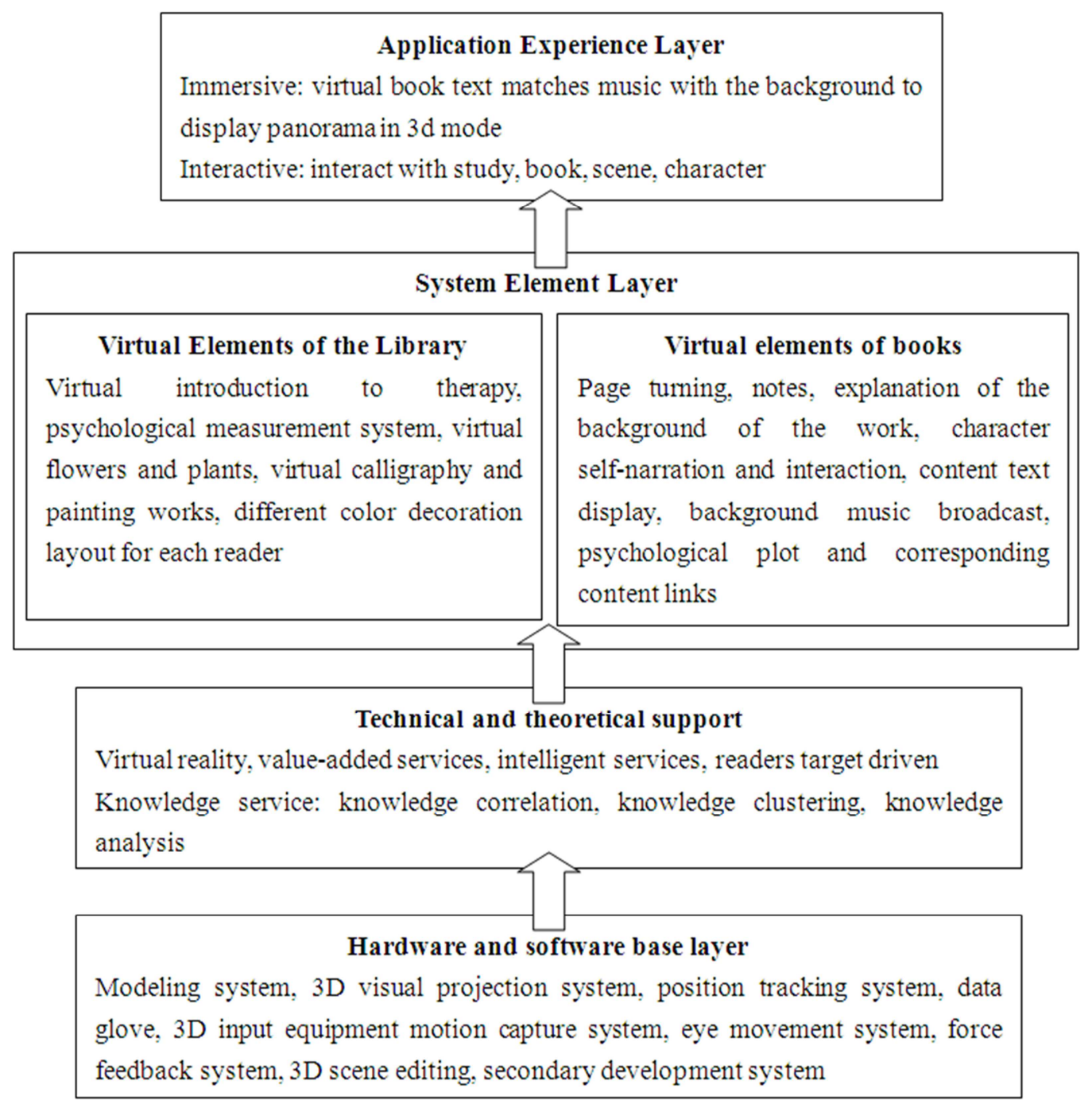

Figure 1. Management Model Diagram of Virtual Reality Bibliotherapy.

Implementation. Virtual reality Bibliotherapy can be realized in a variety of ways, such as application based on mobile phone client and application based on projection display. The former needs the help of a smartphone and virtual reality glasses, through the phone screen to read. It requires little hardware, is easy to operate, but lacks interactivity. The latter uses professional virtual reality device management, high performance computing devices, and virtual reality book 
systems to read books in an immersive and interactive manner. Both augmented reality books and mixed reality books have better models. Hybrid reality technology allows Bibliotherapy participants to seamlessly switch between real books and virtual reality books. Readers can read the book in real life or choose to experience the situation in the book in virtual reality.

The Analysis of Model. Virtual reality Bibliotherapy provides immersive psychological experience. The content design of reading environment matches the needs of readers. Readers can read virtual books, which are presented with text content with music and background in a three-dimensional mode. Readers can easily integrate into the situation, immerse themselves in the virtual world, and carry out identification, catharsis and comprehension. The deep virtual interactive experience is more about arousing reading interest. Readers can walk in the virtual environment, select the book, touch the page, click the text or area, and even step into the scene in the book, travel through time and space, and chat with the characters in the book. The scene is virtual, but the reader's physical and emotional changes are real, it is the reality of virtual mapping, is the extension of human living space and cognition. In the process of therapy, the complex or boring reading content is expressed by visual, auditory and tactile symbols, so as to give full play to human language, logic and other abilities, fully mobilize readers' various perceptual nerves, help readers to deeply understand the content and turn it into personal psychological cognition, and deeply integrate text resources and emotional supply. The management model of virtual reality Bibliotherapy is shown in figure 1 .

Based on the virtual elements in the system model, the researchers conducted a Likert five-point scale survey on the participating readers of Bibliotherapy to analyze their importance. Specific data are shown in table 1.

Table 1. Factor Scale Score of Management Model of Virtual Reality Bibliotherapy.

\begin{tabular}{llll}
\hline Virtual elements & Scale score & Virtual elements & Scale score \\
\hline Virtual introduction to therapy & 4.12 & Page turning & 3.41 \\
psychological measurement system & 4.67 & notes & 3.46 \\
virtual flowers and plants, & 3.37 & explanation of the background of the work \\
virtual calligraphy and painting works & 3.26 & character self-narration and interaction & content text display \\
different color decoration layout for each reader & 3.74 & background music broadcast \\
psychological plot and corresponding content links & 3.95 & 3.87 & 3.33 \\
\hline
\end{tabular}

It can be analyzed from the survey and scale calculation that the readers generally accept the virtual elements in the model positively and the model design is effective. Readers are more likely to agree with the general, technical and informative elements such as therapy introduction, psychological measurement and background explanation, while the weak technical and popular elements such as virtual display of contents and environmental beautification are relatively weakened.

Difficulty Analysis of Therapy Management. First of all, the virtual book products that Bibliotherapy relies on are mainly experience services and assistance designed by developers. Most of the application scenes of the products are based on people's intuitive feelings and interactive experience. Most of the creativity is enlightening and exploratory, which is not close to the actual needs of readers and lacks the sense of experience in real scenes. The development of virtual reality services is complicated and the input cost is relatively high. Developers lack confidence in the market prospect of reading virtual service products. In the process of product design, they seldom investigate the needs of library users and lack direct communication with users. Secondly, users' immersion in the virtual world is mainly realized by visual, tactile and auditory illusion, among which the most important is the illusion of visual perception, and the user's visual illusion is mainly realized by artificial three-dimensional image processing. The basic principle of artificial $3 \mathrm{~d}$ images is to display slightly different images in the left and right eyes, thus creating a stereoscopic effect, but it also leads to axis focusing conflicts. Usually, our eyes will automatically adjust the focal length to focus on objects that are far away or very close. However, in virtual reality images, objects will be displayed on a flat surface, and the distance between them is not obvious. But the eye has to focus so frequently that it can't tell what to see and what to focus on. Therefore, virtual reality vertigo will appear [15].

\section{Conclusion}

Virtual reality provides readers with personalized, humanized and enjoyable services, enabling readers to experience immersive and interactive Bibliotherapy, with advantages that traditional books or e-books cannot match. Such service experience can stimulate and attract more psychological patients to participate, improve the utilization rate of Bibliotherapy, and increase the spread and promotion of Bibliotherapy. Library's function of preserving cultural heritage, social education, transmitting scientific information, developing intellectual resources and providing cultural entertainment has been fully manifested.

The promotion of virtual reality Bibliotherapy requires the combination of knowledge service institutions, virtual book publishing institutions and virtual reality technical teams, as well as the integration of the knowledge of experts in the field of book information research, so as to undertake the social psychological education and guidance in the new normal period and assist the construction of psychological harmony in Chinese society at a low cost.

\section{Acknowledgements}

This paper is supported by University philosophy and social 
science research project in Jiangsu (Research on the influence of emotion-measurement assisted Bibliotherapy on the cultivation mechanism of psychological civilization of college students -- a case study of agricultural engineering students, item No.: 2018SJA1050), Jiangsu province school youth league research project (Improving the organizational vitality of the youth league in university libraries -- a study on the construction mechanism of Bibliotherapy for college students' league members, item No.: YB2018005).

\section{References}

[1] Jacqueline Pfeiffer. Reading Science [J]. Science Scope, 2016 (11): 86-87.

[2] Chen Shuang. On Arnold Berliner's Theory of Reader Reading [D]. Jinan: Shandong Normal University, 2019.

[3] Meer Yael. Calibration of Self-Reports of Anxiety and Physiological Measures of Anxiety While Reading in Adults With and Without Reading Disability [J]. Dyslexia, 2016 (8): 67-84.

[4] Wang Bo. Definition of Bibliotherapy [J]. Book information and knowledge, 2005 (1): 98-102.

[5] Zhu Zhiyu, Zhu Danyang. Reading Driven by Virtual Reality: a Perspective Based on Embodied Cognition [J]. The Forum of Media, 2019, 2 (20): 110-114.

[6] Xu Huiyan, Chen Wei. Turning to Embodied Cognition in Reading: Rooted in Physical and Imaginative Manipulation of Learning [J]. Journal of Distance Education, 2018 (1): 106-112.
[7] Sun Ruiying, Wang Xu. The Emotional Regulation of Reading Under the Visual Threshold of "Embodied Cognition" [J]. The Forum of Library (4): 103-110.

[8] Zhang Xiaofei. Research on Cultural Heritage Protection of Potala Palace Integrating Virtual Reality Technology [J]. Tibet Development Forum, 2018 (3): 30-33.

[9] Chang Yuxin. Discussion on the Application of Virtual Reality Technology in Environmental Art Design [J]. Art and Design, 2019 (8): 54-55.

[10] Wang Zhongshun. The Loss of Reading Patience and the Rise of Reading Technology Replacement [J]. The Forum of Library, 2017 (9): 1-7.

[11] Zhang N, Nunes M B, Li J Y. An Investigation of The Use of VR Books To Resolve Difficulties With Access And Reading of Chinese Ancient Books [C]. IADIS Conference on ICT, Society, and Human Beings. ACM, 2018: 131-140.

[12] Zhang Xiaofei, Feng Yun, Pu Weihua. The application prospect of virtual reality technology in library service innovation [J]. Library Work and Research, 2019 (6): 82-85.

[13] Wu Jianzhong. Ten Hot Topics of Library Development are Discussed Again [J]. The Journal of China Library, 2017, 43 (4): 4-17.

[14] Chen Youhua. Discussion on the reading promotion research paradigm [J]. The Forum of Library, 2018 (3): 81-89.

[15] Viirre Erik, Ellisman Mark. Vertigo in virtual reality with haptics: case report [J]. Cyberpsychology \& Behavior, 2004, 6 (4). 